\title{
Effects of a Chronic Protocol of Stretching about the Capacity of a Muscle in Sustaining Prolonged Efforts
}

\author{
Aristela de Freitas Zanona ${ }^{1 *}$, Micael Deivison de Jesus Alves², Giselle Machado Magalhães Moreno ${ }^{3}$, Ricardo \\ Aurelio Bento Silva ${ }^{2}$ and Raphael Fabricio de Souza ${ }^{2}$ \\ ${ }^{1}$ Department of Occupational Therapy, Federal University of Sergipe - UFS, Brazil \\ ${ }^{2}$ Department of Physical Education, Federal University of Sergipe-UFS, Brazil \\ ${ }^{3}$ Department of Physiology and pharmacology, Federal University of Pernambuco-UFPE, Brazil \\ Submission: January 25, 2018; Published: February 06, 2018 \\ *Corresponding author: Aristela de Freitas Zanona, Department of Occupational Therapy, Federal University of Sergipe-UFS, Brazil, \\ Email: arisz_to@yahoo.com.br
}

\begin{abstract}
The aim of this study was to evaluate the effects of the chronic stretching on muscle fatigue in male young adults. Thirty volunteers were randomly divided into two groups: Stretching Group ( $S G, n=15)$, the participants performed a stretching exercise program for hamstring muscle, three times a week, for six weeks and Control Group ( $C G, n=15)$. The protocol consisted of three different stretching exercises, performed in 3 repetitions of 30 seconds, totalizing 270 seconds. The Range of Motion (ROM) of the knee was evaluated and the isometric peak torque of the hamstring muscles. The rate of reduction in force was evaluated as the resultant of the maximum and minimum isometric peak torque, which was generated by the hamstring muscles and by the integral area of torque-time was calculated and it provided the impulse during the test execution. Parametric results were analyzed by ANOVA two-factor, post hoc Fisher and for the non parametric data was used the Kruskal Wallis test $(p \leq 0,05)$. The post $S G$ increased the ROM in comparison to the post CG $\left(159 \pm 1.5^{\circ}\right.$ vs. $\left.136.1 \pm 2.5^{\circ}\right)(p<0,001)$. There was no change in peak torque, rate of reduction in force and impulse. The chronic practice of the stretching exercises increases the ROM without interfering the capacity of force maintenance of the hamstring muscles.
\end{abstract}

Keywords: Muscle stretching exercises; Muscle fatigue; Peak torque; Flexibility

\section{Introduction}

Stretching exercises are commonly included in physical training programs with the aim of increasing in Range of Movement (ROM) and improvement on musculoskeletal symptoms and performance [1-4]. Reductions on the force and performance have been observed immediately before the stretching [5-7], so it seems to exist an acute negative effect. On the other hand, if the stretching exercises are performed regularly (chronic effect) the rises in ROM are also accompanied by improvements in muscle force and performance $[8,9]$. Therefore, the positive effects of those exercises on performance are important to activities which require high contraction capacity (maximum force). The effects of the chronic stretching on contraction capacity can also affect the mechanism of muscle fatigue, so it alters the performance and involves sensory and motor processes [10]. Sensory mechanisms adaptable by stretching are observed in mechanoreceptors activated by joint deformation and mainly in the efferent feedback of motor units in intrafusal gamma striated fiber. These fibers have a motor function and they produce changes on the viscoelastic properties of the muscle [11]. When the properties are affected by fatigue they contribute to inhibition of motoneuron excitability. On the other hand, motor actions depend on the quality of the afferent and efferent impulse originated in the peripheral area (joints and muscles), which can show plastic deformations due regular practice of stretching [12]. Thus, improvements on the excitation-contraction mechanisms may result in increases in contractile force.

Studies in animals have reported increases in serial sarcomere number, cross-sectional area [13,14], protein synthesis [15] and rise in responsiveness of muscle spindle [16], which cause remodeling of the viscoelastic properties of the musculotendinous units. This plasticity may improve in quantity, duration and muscle contraction velocity. Thus, they can increase the capacity of a muscle sustain prolonged efforts. Muscle fatigue is resulted from failures and reduction in neuromuscular system capacity to generate force [17]. Therefore, it is important to understand the mechanisms associated to the reduction processes of performance in order to establish strategies to delay or decrease it. Researches in chronic effect of stretching about muscle performance are not known. In this way, the present study had as objective to evaluate the effects of a chronic protocol of stretching about the capacity of a muscle in sustaining prolonged efforts. 


\section{Materials and Methods}

Thirty men participated voluntarily in this research $(22,1$ $\pm 0,2$ years old; $71,6 \pm 5,2 \mathrm{~kg} ; 170,0 \pm 0,17 \mathrm{~cm}$ ). They were randomized [18] into two groups: Stretching Group (SG; n=15) and Control Group (CG; $n=15$ ). The experimental procedures were performed according the ethic patterns of International Journal of Sports Medicine [19]. The Stretching Group performed 3 types of static stretching exercises for hamstring [6]. Each stretching movement was made in a gradual and slow manner until the beginning of discomfort. The exercises were hold for 30 seconds at the same position, and they were repeated 3 times with a break of 10 seconds between each repetition. This program was realized 3 times a week, during 6 weeks [20].

\section{Determination of Hamstring Muscle Flexibility}

Flexibility was evaluated by measuring the knee extension ROM from a flexed position of hip joint using a universal goniometer (Dysport). Firstly, the volunteer kept himself/herself in supine position with the hip and the knee of the limb to be tested effortless flexed in 90 o. From this position, the knee was effortlessly and slowly extended until the start of the tension and the discomfort in the knee flexor muscles. The full knee extension was considered as $0^{\circ}$ and it was utilized as reference to indicate the limitation of the knee joint extension $[16,21,22]$. Three measurements were taken, and the arithmetic mean of them used for analysis.

\section{Isometric Torque}

Isometric peak torque was measured by the maximum torque generated by the knee flexor muscles (hamstrings). The isometric peak torque was determined by the product of isometric peak force of the hamstrings and the limb length, which was considered from the fixing point of load cell cable to the knee joint center. The isometric force was determined by a load cell (Kratos, model CZC500) that was fixed to an inextensible cable and attached near the malleolus by a Velcro system that was placed close to the malleolus. The Figure 1 shows schematically the position of the participants for measurements of isometric force [23].

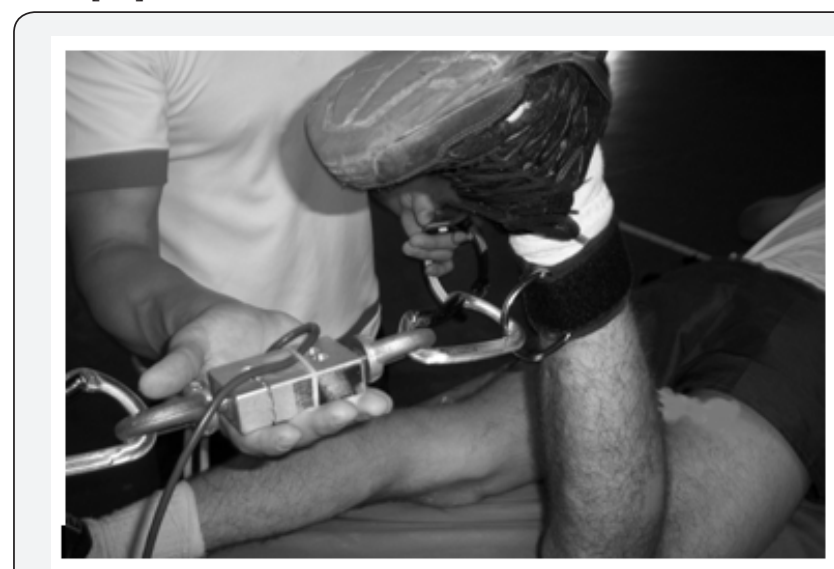

Figure 1: Position of the participants for measurements of isometric force.
The load cell signals were amplifier (Kratos, model IK- 1C), and they were also converted to a digital format (National Instruments, model NI USB 6218) with a frequency of acquisition of $1000 \mathrm{~Hz}$, which allowed the subsequent reconstruction of force-time curve. The participants were instructed to perform the knee flexion movement the faster as possible and hold it for 30 seconds continuously without relaxing in one maximum repetition. Each volunteer performed a five-minute warm up on a stationary exercise bike with no resistance and with $50 \%$ to $75 \%$ of the maximum cardiac frequency [24], before the evaluations and the stretching exercises. The familiarization session was conducted seven days before the evaluation with the aim of reducing variability and to minimize possible learning effects. The integral area of torque-time was calculated and it provided the impulse during the test execution [25]. Furthermore, the time that the effort was performed was calculated. The capacity of the participants to resist the effort was determined by the rate of reduction in force, which was determined by the relative difference between the maximum peak torque at the beginning of the test and the minimum peak observed at the end in relation to time $[26,27]$. The Figure 2 shows schematically the variables analyzed in the study.

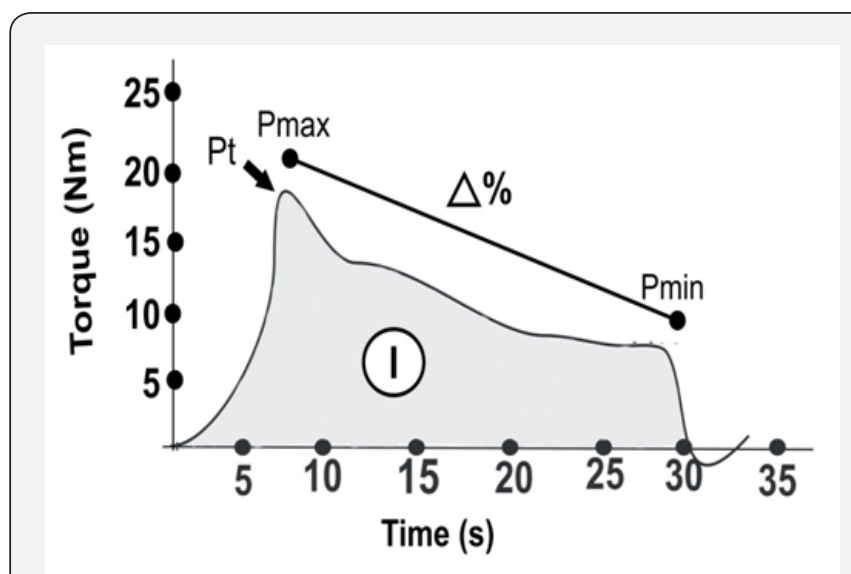

Figure 2: Scheme of the force test.

$\mathrm{Pt}=$ Peak Torque; I= Impulse; $\mathrm{Pmax}=$ Maximum peak torque; Pmin $=$ Minimum peak torque; $\Delta \%=$ Peak torque variation.

\section{Analysis of the Results}

It was used a descriptive statistic as mean \pm standard deviation. For the data analysis, the normality and the homogeneity were evaluated with Shapiro-Wilk e Levene tests, respectively. When the values were parametric the comparisons were performed by analysis of variance (ANOVA- two-factor), followed by post hoc Fisher. When non-parametric they were compared using the Kruskal Wallis. It was used Statistica Software (version $7.0 \AA$ ) for all the statistical analysis and it was also adopted a significance level of $5 \%(\mathrm{p}<0.05)$.

\section{Results}

The knee extension motion's range of the GA group increased after the stretching protocol, both in intra comparison (151 \pm $2^{\circ}$ vs $124 \pm 3^{\circ}$, p $\left.<0.001\right)$ and groups comparison $\left(159 \pm 1^{\circ}\right.$ vs 
$\left.132.12 \pm 1.50^{\circ}, \mathrm{p}<0.001\right)$. There were no differences in torque peak of hamstrings, strength maintenance rate and impulse

within and between groups ( $p>0.05)$. The results are reported in Table 1.

Table 1: ROM, isometric peak torque, rate of reduction in force and impulse.

\begin{tabular}{|c|c|c|c|c|}
\hline & \multicolumn{2}{|c|}{ PRE } & \multicolumn{2}{|c|}{ POST } \\
\hline & CG & SG & CG & SG \\
\hline ROM & $131.0 \pm 2^{\circ}$ & $124.1 \pm 3^{\circ}$ & $136.1 \pm 2.50^{\circ}$ & $159.12 \pm 1.50^{\circ} *$ \\
\hline $\mathrm{Pt}(\mathrm{Nm})$ & $18.50 \pm 3.32$ & $19.43 \pm 5.65$ & $19.34 \pm 4.34$ & $20.12 \pm 6.42$ \\
\hline RF (\%) & $49.32 \pm 11.00$ & $50.32 \pm 21.12$ & $48.23 \pm 19.12$ & $51.11 \pm 12.22$ \\
\hline I (Nm.s) & $405.23 \pm 154.23$ & $395.12 \pm 187.23$ & $415.16 \pm 112.13$ & $401.34 \pm 142.86$ \\
\hline
\end{tabular}

CG: Control Group; SG: Stretching Group. ROM = Range of Motion; Pt= Peak torque, RF= Rate of reduction in force, I= Impulse. The data are mean \pm standard deviation. ${ }^{*} \mathrm{p}<0,05$ when it is compared to pre GA and post CG.

\section{Discussion}

The six-week stretching program applied in young adults in which the present study is based was effective to increase in $17 \%$ the knee motion's range. The benefits were greater than in other studies in which the amplitude of movement was only $6 \%$ [16]. Probably, the shorter length of the training period (5 vs 6 weeks) and the total volume (90 vs 270S) may explain the discrepancies between the data presented in this study and by Roberts and Wilson's reports. Moreover, Rancor et al. [28] found increments of $21 \%$ with a smaller amount of training (120s), but with a longer length ( 8 weeks), in which the stretching exercises were administered. Therefore, the volume and frequency of training seem to be crucial and must be controlled so that the gains can be obtained. The increments in the motion's range can be attributed to several mechanisms which involve changes on the particular tissues, tendon and muscles. Changes in the viscoelastic properties of muscle tissue may have decreased muscle tension throughout the training period and allowed changes in muscle extensibility [15].

Furthermore, the decrease of excitability or synaptic transmission of motor neurons afferent fibers and the reduction of muscle spindles' sensitivity in response to the exercise program may also have contributed to the increasing of the tolerance to stretching stimuli [29]. Thus, the activity of the muscle-tendon and joint proprioceptors could have been mitigated and could have helped reduce stiffness, aiming muscle length and ROM increasing [9]. The torque peak, impulse and ability to maintain strength remained unchanged after the training program involving stretching exercises. Other studies also found no gains in young adults on the eccentric isokinetic torque peak, after a four-week program of exercises performed three times a week $[30,31]$. Also, in a study that lasted 12 weeks of training (two sessions a week with three repetitions of 30 s), Nobrega et al. [32], there were not found any significant increases in muscle strength in the 1RM test. However, others [33] that evaluated concentric isokinetic torque after six-week training program with stretching exercises (5 sessions per week) in young adults found gains of $3.2 \%$. Therefore, programs that involve stretching exercises to improve the contractile capacity should be performed in periods longer than 5-6 weeks and with volumes of not less than 30 s. The small influence of the program of stretching exercises on the pulse and support rate of the isometric strength may be associated with mechanisms involved in or synergistic co- activations muscle actions.

The mechanisms are associated with activation of other muscles that act together with the main agonist muscles, being observed as muscular ability, the activation of slow-twitch motor units that can sustain an isometric force longer than fasttwitch motor units [34]. In general, these mechanisms have been interpreted as a form of compensation and muscle strategy that aims to support muscle strength [35]. Future studies involving muscle activation parameters are needed to confirm these speculations. Although no significant changes were observed on the contractile capacity, the stretching protocol did not produce reductions in torque peak, which are usually found immediately after application of flexibility exercises [36,37]. Therefore, stretching protocols carried out regularly are effective to produce increases on the motion range, but do not produce a decreasing of the muscle strength production's maximum ability. The studies aiming the investigation on the eccentric isokinetic torque as well as electromyography evaluations of synergist and antagonist muscles are needed for the chronic effects of stretching on the contractile capacity can be better understood.

\section{References}

1. Decoster LC, Cleland J, Altieri C, Russell P (2005) The effects of hamstring stretching on range of motion: A systematic literature review. J Orthop Phys Ther 35(6): 377-387.

2. Laroche DP, Lussier MV, Roy SJ (2008) Chronic stretching and voluntary muscle force. J Strength Cond Res 22(2): 589-596.

3. Maragoni AH (2010) Effects of intermittent stretching exercises at work on musculoskeletal pain associated with the use of a personal computer and the influence of media on outcomes. Work 36(1): 27-37.

4. Shrier I (2004) Does stretching improve performance? A systematic and critical review of the literature. Clin J Sport Med 14(5): 267-273.

5. Cramer JT, Housh TJ, Weir JP, Johnson GO, Coburn JW, et al. (2005) The acute effects of static stretching on peak torque, mean power out, electromyography, and mechanomyography. Eur J Appl Physiol 93(56): $530-539$

6. Herda TJ, Cramer JT, Ryan ED, Mchugth MP (2008) Acute Effects of Static versus dynamic stretching on isometric peak torque, electromyography, an mechanomyography of the biceps femoris muscle. J Strength Cond Res 22(3): 809-817. 
7. Robbins JW, Scheuermann BW (2008) Varying Amouts of Acute Static Stretching and its Effect on Vertical Jump Performance. J Strength Cond Res 22(3): 781-786.

8. Kokkonen J, Nelson AG, Eldregde C, Winchester JB (2007) Chronic static stretching improves exercise performance. Med Sci Sports Exerc 39(10): 1825-1831.

9. Magnusson SP (1998) Passive properties of human skeletal muscle during stretch maneuvers. Scand J Med Sci Sports 8(2): 65-77.

10. Enoka RM, Stuart DG (1992) Neurobiology of muscle fatigue. J Appl Physiol 72(5): 1631-1648.

11. Lee HM, Liau JJ, Cheng CK, Tan CM, Shih JT (2003) Evaluation of shoulder proprioception following muscle fatigue. Clin Biomech 18(9): 843-847.

12. Weppler HC, Magnusson SP (2010) Increasing Muscle Extensibility: A matter of increasing length or modifying sensation?. Phys Ther 90(3): 438-449.

13. Coutinho EL, Gomes ARS, França CN, Oishi J, Salvini TF (2004) Effect of a passive stretching on the immobilized soleus muscle fiber morphology. Braz J Med Biol Res 37(12): 1853-1861.

14. Siatras TA, Mittas VP, Mameletzi DN, Vamvakoudis EA (2008) The Duration of the Inhibitory Effects with Static Stretching on Quadriceps Peak Torque Production. J Strength Cond Res 22(1): 40-46.

15. Gajdosik RL, Linden DWV, Mcnair PJ, Williams AK, Riggin TJ (2005) Effects of an eight-week stretching program on the passive-elastic properties and function of the calf muscle of older women. Clin Biomech 20(9): 973-983.

16. Roberts JM, Wilson K (1999) Effect of stretching duration on active and passive range of motion in the lower extremity. Br J Sports Med 33(4): 259-263.

17. Kellis E, Kouvelioti V (2009) Agonist versus antagonist muscle fatigue effects on thigh muscle activity and vertical ground reaction during drop landing. J Electromy and Kinesio 19(1): 55-64.

18. Thomas J, Nelson J, Silvermam S (2005) Research methods in physical activity: Champaign. Human Kinetics, Illinois, USA.

19. Harris DJ, Atkinson G (2011) Update-ethical standards in sport and exercise science research. Int J Sports Med 32(11): 819-821.

20. Bandy WD, Irion JM, Briggler M (1997) The effect of time and frequency of static stretching on flexibility of the hamstring muscles. Phys Ther 77(10): 1090-1096.

21. Gajdosik R, Lusin G (1983) Hamstring muscle tightness. Reliability of an active-knee-extension test. Phys Ther 63(7): 1085-1090.

22. Marques AP, Vasconcelos AAP, Cabral CMN, Sacco ICN (2009) Effect of frequency of static stretching on flexibility, hamstring tightness and electromyographic activity. Braz J Med Biol Res 42(10): 949-953.

23. Bento PCB, Pereira G, Ugrinowitsch C, Rodacki ALF (2010) Peak torque and rate of torque development in elderly with and without fall history. Clin Biomech 25(5): 450-454.

24. Franklin B, Whaley M, Howley E (2000) ACSM's Guidelines for Exercise Testing and Prescription. Lippincott Williams \& Wilkins, Philadelphia, USA.

25. Ruggiero MAG, Lopes VLR (1988) Cálculo numérico, aspectos teóricos e computacionais. McGraw Hill, São Paulo, Brazil pp. 295.

26. Mohr M, Mujika I, Santisteban J, Randers MB, Bischoff R, et al. (2010) Examination of fatigue development in elite soccer in a hot environment: a multi-experimental approach. Scand J Med Sci Sports 20(3): 125-132

27. Terreri ASAP, Greve JMD, Amatuzzi MM (2001) Avaliação isocinética no joelho do atleta. Rev Bras Med Esporte 7(2): 170-174.

28. Rancour J, Holmes CF, Cipriani DJ (2009) The effects of intermittent stretching following a 4-week static stretching protocol: a randomized trial. J Strength Cond Res 23(8): 2217-2222.

29. Guissard N, Duchateau J (2006) Neural aspects of muscle stretching. Exerc Sport Sci Rev 34(4): 154-158.

30. Higgs F, Winter SL (1999) The effect of a four-week proprioceptive Neuromuscular facilitation stretching program on isokinetic torque production. J Strength Cond Res 23(5): 1442-1447.

31. Mchugh MP, Cosgrave CH (2010) To stretch or not to stretch: the role of stretching in injury prevention and performance. Scand J Med Sci Sports 20(2): 169-181.

32. Nobrega ACL, Paula KC, Carvalho ACG (2005) Interaction Between Resistance Training and Flexibility Training in Healthy Young Adults. J Strength Cond Res 19(4): 842-846.

33. Ferreira GNT, Salmela LFT, Guimarães CQ (2007) Gains in Flexibility Related to Measures of Muscular Performance: Impact of Flexibility Muscular Performance. Clin J Sports Med 17(4): 276-281.

34. Brooks SV, Faulkner JA (1991) Forces and powers of slow and fast skeletal muscle in mice during repeated contractions. J Physiol 436: 701-710.

35. Psek JA, Cafarelli E (1993) Behavior of coactive muscles during fatigue. J Appl Physiol 74(1): 170-175.

36. Marek SM, Cramer JT, Fincher AL, Massey LL, Dangelmaier SM, et al. (2005) Acute Effects of Static and Proprioceptive Neuromuscular Facilitation Stretching on Mucle Strength and Power Output. J Athl Train 40(2): 94-103.

37. Secchi K, Morais CP, Cimatti P, Tokars E, Gomes ARS (2008) Efeito do alongamento e do exercício contra resistido no músculo esquelético de rato. Rev Bras Fisioter 12(3): 228-234. 
This work is licensed under Creative

Commons Attribution 4.0 Licens

DOI: 10.19080/JPFMTS.2018.01.555574
Your next submission with Juniper Publishers

will reach you the below assets

- Quality Editorial service

- Swift Peer Review

- Reprints availability

- E-prints Service

- Manuscript Podcast for convenient understanding

- Global attainment for your research

- Manuscript accessibility in different formats

( Pdf, E-pub, Full Text, Audio)

- Unceasing customer service

Track the below URL for one-step submission https://juniperpublishers.com/online-submission.php 